\title{
Old and New Intravenous Inotropic Agents in the Treatment of Advanced Heart Failure
}

\author{
Marco Metra*, Luca Bettari, Valentina Carubelli, Livio Dei Cas \\ Cardiology, Department of Experimental and Applied Medicine, University of Brescia, Civil Hospital of Brescia, Brescia, Italy
}

\begin{abstract}
Inotropic agents are administered to improve cardiac output and peripheral perfusion in patients with systolic dysfunction and low cardiac output. However, there is evidence of increased mortality and adverse effects associated with current inotropic agents. These adverse outcomes may be ascribed to patient selection, increased myocardial energy expenditure and oxygen consumption, or to specific mechanisms of action. Both sympathomimetic amines and type III phosphodiesterase inhibitors act through an increase in intracellular cyclic adenosine monophoshate and free calcium concentrations, mechanisms that increase oxygen consumption and favor arrhythmias. Concomitant peripheral vasodilation with some agents (phosphodiesterase inhibitors and levosimendan) may also lower coronary perfusion pressure and favor myocardial damage. New agents with different mechanisms of action might have a better benefit to risk ratio and allow an improvement in tissue and end-organ perfusion with less untoward effects. We have summarized the characteristics of the main inotropic agents for heart failure treatment, the data from randomized controlled trials, and future perspectives for this class of drugs. (Prog Cardiovasc Dis 2011;54:97-106)

(C) 2011 Elsevier Inc. All rights reserved.
\end{abstract}

Keywords: $\quad$ Heart failure; Low cardiac output; Inotropic agents; Mortality

The prognosis of the patients with heart failure (HF) has been improved by the administration of neurohormonal antagonists and the use of implantable cardioverter defibrillators and cardiac resynchronization devices. ${ }^{1-4}$ However, these therapies only slow HF progression; and many patients progress to a stage of advanced HF, characterized by severe cardiac dysfunction, severe symptoms, and poor prognosis. ${ }^{5,6}$ At this stage, impaired left ventricular (LV) pump function plays a pivotal role as a cause of dyspnea and fatigue, poor peripheral perfusion, and end-organ dysfunction. ${ }^{7}$ Improvement in cardiac function through agents with inotropic properties is, therefore, an attractive option for such patients as the most reliable means for improving cardiac output and

Statement of Conflict of Interest: see page 104.

* Address reprint requests to Marco Metra, MD, Cardiology, c/o Spedali Civili, Piazzale Spedali Civili 1, Brescia 25123, Italy.

E-mail address: metramarco@libero.it (M. Metra). peripheral perfusion. However, all currently available inotropic agents have adverse effects; and their use has been associated with increased mortality. ${ }^{8-11}$ An ideal inotropic agent able to restore tissue perfusion in the absence of adverse effects is not available, but new agents with different biologic targets and better safety profiles are under development.

\section{The clinical problem}

Fluid overload and pulmonary congestion with elevated LV end-diastolic pressure and pulmonary wedge pressures are the main causes of HF hospitalizations. ${ }^{3,12-14}$ Reduced cardiac output and peripheral hypoperfusion may also be important in some patients. These patients, whose prevalence can be estimated at approximately $10 \%$ to $15 \%$ of the overall patients admitted for acute HF, have low blood pressure, signs of kidney and/or liver dysfunction, and severe LV systolic and diastolic 
Abbreviations and Acronyms

$\mathbf{A R}=$ adrenergic receptor

$\mathbf{A T P}=$ adenosine

triphosphate

ATPase $=$ adenosine

triphosphatase

$\mathbf{B N P}=$ brain natriuretic peptide

$\mathbf{c A M P}=$ cyclic adenosine monophoshate

$\mathbf{C I}=$ confidence interval

$\mathbf{C R F}=$ corticotrophinreleasing factor

FFA $=$ free fatty acid

$\mathbf{H F}=$ heart failure

$\mathbf{I V}=$ intravenous

$\mathbf{L V}=$ left ventricular

LVEF = LV ejection fraction

NYHA = New York Heart

Association

PDE-I $=$ phosphodiesterase inhibitor

PDE3-I $=$ phosphodiesterase 3 inhibitor

$\mathbf{R y R}=$ ryanodine receptor

SBP $=$ systolic blood pressure

SERCA = sarcoplasmic reticulum calcium ATPase

$\mathbf{S R}=$ sarcoplasmic reticulum

SURVIVE = survival of patients with acute heart failure in need of intravenous inotropic support

$\mathbf{V o}_{2}=$ oxygen consumption per unit time

wet patients") (Table 1). ${ }^{8-11,15}$ Hypotension is the primary sign of hypoperfusion and low cardiac output. $6,10,16$ Other signs of hypoperfusion include cold, clammy skin, renal impairment, liver dysfunction, and/or impaired mentation. Clinical assessment is sufficient when urgent treatment is needed. Echocardiography, when available, should show signs of systolic dysfunction with dilated, hypokinetic ventricles. Until agents with predominant effects on diastolic function become available, it is unlikely that inotropic agents may be useful in patients with $\mathrm{HF}$ and preserved LV ejection fraction (LVEF). To minimize their untoward effects, inotropic agents should be administered at the lowest effective doses and discontinued as soon as organ perfusion is restored and/or congestion is relieved.

The current American College of Cardiology/American Heart Association guidelines state that inotropic agents are indicated to improve symptoms and end-organ function in patients with low output syndrome, LV systolic dysfunction, and systolic blood pressure (SBP) less than $90 \mathrm{~mm}$ $\mathrm{Hg}$ despite adequate filling pressure. ${ }^{1}$ Inotropic agents may also be indicated as bridge to heart transplant or mechanical assist device implantation or as palliation for symptoms in end-stage HF. ${ }^{17}$

These indications are in agreement with the European Society of Cardiology guidelines, which state that inotropic agents are indicated for patients with low SBP or a low measured cardiac index in the presence of signs of hypoperfusion or congestion. They also state that inotropic agents should be reserved for patients with dilated, hypokinetic ventricles and, when indicated, should be administered as early as possible and discontinued as soon as organ perfusion is restored and/or congestion is reduced. ${ }^{2,18}$ Differences in the indications to different inotropic agents are outlined in these guidelines with levosimendan indicated also for patients with a SBP greater than $100 \mathrm{~mm} \mathrm{Hg}$ and dopamine indicated for patients with a SBP less than $90 \mathrm{~mm} \mathrm{Hg.}{ }^{2}$

The Heart Failure Society of America guidelines expand the indication of inotropic agents also to patients with evidence of fluid overload and lack of response to intravenous (IV) diuretics and/or to patients with reduced or worsening renal function. Regarding safety, the Heart Failure Society of America guidelines state that the administration of inotropic agents should be accompanied by continuous monitoring of blood pressure and cardiac rhythm with drug withdrawal or dose reduction to be considered in case of symptomatic hypotension or development of tachyarrhythmias. ${ }^{3}$

Despite consistency between different guidelines, recent registries have shown wide variations in the proportion of patients receiving inotropic agents. The proportion of patients hospitalized for acute HF and receiving inotropic agents ranges from 7\% in the Organized Program to Facilitate LifeSaving Treatment in Hospitalized Patients with Heart Failure (OPTIMIZE-HF) registry ${ }^{16}$ to nearly $25 \%$ in the EuroHeart Failure Survey II. ${ }^{19}$ Although low SBP is considered a major indication for inotropic agents, this does not seem to occur in clinical practice ${ }^{16,19,20}$ so that patients may receive inotropic agents even in the absence of clear indications.

\section{Current inotropic agents}

\section{Dobutamine}

Dobutamine is the prototype of inotropic agents acting through $\beta$-adrenergic receptor (AR) stimulation (Table 2). It has high affinity for $\beta_{1}$-ARs whose stimulation causes 
Table 1

Recommendations for treatment with inotropic agents according to current major guidelines for the treatment of HF (shown in alphabetical order)

\begin{tabular}{|c|c|c|}
\hline Society & Indications & $\begin{array}{l}\text { Class of Recommendation - } \\
\text { Level of Evidence }\end{array}$ \\
\hline \multirow[t]{4}{*}{$\begin{array}{l}\text { American College of Cardiology } \\
\text { Foundation/American } \\
\text { Heart Association }^{1}\end{array}$} & $\begin{array}{l}\text { Clinical evidence of hypoperfusion with hypotension and elevated cardiac } \\
\text { filling pressures (eg, elevated jugular venous pressure and/or pulmonary } \\
\text { wedge pressure) } \rightarrow \text { to maintain systemic perfusion and preserve end-organ } \\
\text { performance, while more definitive therapy is considered. }\end{array}$ & $\mathrm{I}-\mathrm{C}$ \\
\hline & Palliation of symptoms in patients with refractory end-stage HF. & $\mathrm{IIb}-\mathrm{B}$ \\
\hline & $\begin{array}{l}\text { Routine intermittent infusions are not recommended for patients with } \\
\text { refractory end-stage HF. }\end{array}$ & III - A \\
\hline & $\begin{array}{l}\text { Use in normotensive patients with acute decompensated HF without } \\
\text { evidence of decreased organ perfusion is not recommended. }\end{array}$ & III - B \\
\hline European Society of Cardiology ${ }^{2}$ & $\begin{array}{l}\text { Low output state (low SBP and/or measured CI) + signs of hypoperfusion or } \\
\text { congestion despite the use of vasodilators and/or diuretics + dilated, } \\
\text { hypokinetic ventricles to improve symptoms } \\
\text { Administered as early as possible/withdrawn as early as organ perfusion is } \\
\text { restored and/or congestion reduced }\end{array}$ & IIa - B \\
\hline \multirow[t]{5}{*}{ Heart Failure Society of America ${ }^{3}$} & $\begin{array}{l}\text { Patients with advanced HF and low output syndrome; particularly if } \mathrm{SBP}<90 \\
\mathrm{~mm} \mathrm{Hg} \text { and/or symptomatic hypotension despite adequate filling pressure. }\end{array}$ & $\mathrm{C}$ \\
\hline & $\begin{array}{l}\text { Patients with evidence of fluid overload if they respond poorly to IV diuretics } \\
\text { or have diminished or worsening renal function. }\end{array}$ & $\mathrm{C}$ \\
\hline & $\begin{array}{l}\text { Not recommended unless left heart filling pressures elevated/CI severely } \\
\text { impaired, based on direct measurement or clear clinical signs. }\end{array}$ & $\mathrm{C}$ \\
\hline & $\begin{array}{l}\text { Administration in the setting of acute decompensated HF should be } \\
\text { accompanied by continuous or frequent BP monitoring and continuous } \\
\text { monitoring of cardiac rhythm. }\end{array}$ & $\mathrm{C}$ \\
\hline & $\begin{array}{l}\text { If symptomatic hypotension or worsening tachyarrhythmias develop } \\
\text { during administration, discontinuation or dose reduction should be considered. }\end{array}$ & $\mathrm{C}$ \\
\hline
\end{tabular}

Abbreviation: BP, blood pressure.

an increase in intracellular cyclic adenosine monophoshate (cAMP) concentration with secondary protein kinase activation, sarcolemma calcium-channel opening, and sarcoplasmic reticulum (SR) calcium release. Calcium binding to troponin $\mathrm{C}$ removes the inhibitory effect of troponin $\mathrm{I}$ and allows actin myosin interaction and sarcomere contraction. The increase in the intracellular cAMP and calcium concentrations plays, therefore, a pivotal role for the dobutamine inotropic effects.

Dobutamine administration has beneficial short-term hemodynamic effects with an increase in cardiac output and decrease in pulmonary wedge pressure in patients with HF. However, it also increases the heart rate and the conduction velocity in the atrioventricular node, with increased heart rate in patients with atrial fibrillation. ${ }^{18,21}$
Dependency on $\beta_{1}$-ARs is a major limitation of this agent. The hemodynamic response to dobutamine can be blunted by concomitant $\beta$-blocker therapy and $\beta$-AR downregulation, and this causes interindividual variability in the response to dobutamine. ${ }^{22,23}$ As $\beta_{1}$-AR downregulation is secondary to prolonged exposure to the agonist, tolerance development with decrease in the hemodynamic response to dobutamine has been described after days of continuous dobutamine infusion. ${ }^{24}$

Dobutamine has a milder effect on $\beta_{2}$-ARs, which cause vascular smooth muscle relaxation. This effect is partially counterbalanced by $\alpha-1$ AR stimulation so that dobutamine net effects on the peripheral vessels are of mild vasodilation or neutral. $\alpha-1-$ Mediated peripheral vasoconstriction can be shown during concomitant $\beta_{2}$ -

Table 2

Inotropic agents currently available

\begin{tabular}{lll}
\hline Drug & Mechanism & $\begin{array}{l}\text { Class of Recommendation - Level of Evidence } \\
\text { (According to 2008 ESC guidelines) }\end{array}$ \\
\hline Dobutamine & $\begin{array}{l}\text { Predominant } \beta_{1} \text {-AR agonist with } \beta_{2} \text {-AR } \\
\text { and } \alpha_{1} \text {-AR agonist properties }\end{array}$ & IIa $-\mathrm{B}$ \\
Dopamine & DA1-DA2, $\beta_{1}-\mathrm{AR}, \alpha-\mathrm{AR}_{1}$ agonist & $\mathrm{IIb}-\mathrm{C}$ \\
Milrinone/enoximone & PDE3-Is & IIb $-\mathrm{B}$ \\
Levosimendan (not available in the US) & Myofilament $\mathrm{Ca}^{2+}$ sensitizer & IIa $-\mathrm{B}$ \\
& ATP-sensitive $\mathrm{K}^{+}$channel activator & \\
& PDE-I &
\end{tabular}

Abbreviations: DA, dopaminergic; ESC, European Society of Cardiology. 
adrenergic blockade as when patients treated with carvedilol receive dobutamine infusion. ${ }^{22}$

Dobutamine administration has been associated with an increased risk of death. The first study showing this was a retrospective analysis from the Flolan International Randomized Survival trial (FIRST). This was a randomized controlled trial of continuous IV epoprostenol plus conventional therapy vs conventional therapy alone, in patients with advanced $\mathrm{HF}$, prematurely terminated for a strong trend toward decreased survival in the patients treated with epoprostenol. An analysis of the patients included in this trial showed that those on dobutamine infusion (mean dose, $9 \mu \mathrm{g} / \mathrm{kg}$ per minute; range, 5-12 $\mu \mathrm{g}$ / $\mathrm{kg}$ per minute; median duration, 14 days) had higher rate of adverse events (worsening HF, need for vasoactive medications, resuscitated cardiac arrest, myocardial infarction, and total mortality; $85.3 \%$ vs $64.5 \% ; P=.0006$ ) and a higher mortality $(70.5 \%$ vs $37.1 \% ; P=.0001)$ compared with the others. ${ }^{25}$ Further studies and a metaanalysis confirmed the increased risk of death associated with dobutamine infusion. ${ }^{26}$ It is, however, likely that this occurs mostly with prolonged infusions and/or the administration of relatively high doses (ie, $>5 \mu \mathrm{g} / \mathrm{kg}$ per minute). Despite its limitations and although this may be related to the lack of valid alternatives, dobutamine remains useful for the short-term treatment of patients with low cardiac output and peripheral hypoperfusion.

\section{Dopamine}

When administered at low doses $(0.5-3 \mu \mathrm{g} / \mathrm{kg}$ per minute), dopamine stimulates dopaminergic 1 and dopaminergic 2 receptors with splanchnic and renal vasodilation and an increase in renal blood flow. At higher doses (3-5 $\mu \mathrm{g} / \mathrm{kg}$ per minute), dopamine binds to $\beta_{1}$-receptors and increases norepinephrine release from sympathetic nerve terminals with an increase in cardiac contractility and heart rate. At even higher doses $\left(5-20 \mu \mathrm{g} / \mathrm{kg}\right.$ per minute), $\alpha_{1}$-Receptor-mediated vasoconstriction dominates with an increase in peripheral vascular resistance. ${ }^{27,28}$

Dopamine is often used to improve diuresis and renal blood flow in patients with acute HF or at risk for acute renal failure. In the recently completed Dopamine in Acute Decompensated Heart Failure trial, 60 patients with acute HF were randomized to a continuous 8-hour infusion of either high-dose furosemide $(20 \mathrm{mg} / \mathrm{h})$ or low-dose furosemide $(5 \mathrm{mg} / \mathrm{h})$ combined with low-dose dopamine. $^{29}$ Both strategies had a similar effect on diuresis and dyspnea score. Worsening renal function, defined as a greater than $0.3 \mathrm{mg} / \mathrm{dL}$ rise in serum creatinine from baseline to 24 hours, was more frequent in the highdose diuretic group $(30 \%)$ than in the dopamine group $(6.7 \%)$. Length of stay and 60-day mortality or rehospitalization rates were similar between the 2 groups. The study has some limitations, in particular, the small number of patients, which limits the ability to draw conclusions regarding the effects on outcomes. However, it confirms previous studies regarding the favorable effects of dopamine on diuresis and renal function with a prospective, randomized study design. ${ }^{29}$

The favorable results of small mechanistic studies are, however, contradicted by studies aimed at the assessment of the effects on outcomes. A meta-analysis of 61 trials, including 3359 patients at risk for acute renal failure, has shown an increase in diuresis during the first 24 hours of dopamine administration in the absence of any difference in serum creatinine levels, rate of acute renal failure development, and short-term mortality but with a tendency toward a greater rate of adverse events. ${ }^{30}$ Thus, despite favorable data from small studies, no data have shown favorable effects of dopamine infusion on major outcomes, defined as mortality, rehospitalizations, or prevention of renal replacement therapy. ${ }^{18}$

\section{Phosphodiesterase inhibitors}

Phosphodiesterase 3 inhibitors (PDE3-Is) increase cAMP level by inhibiting its breakdown within the cell. Thus, their mechanisms of action and effects on cardiac function are similar to those of $\beta_{1}$-AR agonists. The PDE3-Is act, however, downstream the $\beta_{1}$-AR; and thus, their actions are independent from $\beta_{1}$-ARs density but not from cAMP concentrations and from ongoing $\beta$-blocker therapy. ${ }^{18,22}$ Phosphodiesterase inhibitors (PDE-Is) have also greater vasodilating activity, compared with dobutamine, mediated by direct effects of cAMP in the vascular smooth muscle cells. This vasodilatory activity may cause hypotension and further peripheral and coronary hypoperfusion in patients who are already hypotensive at baseline and with low ventricular filling pressure. ${ }^{6,10,11}$ Similar to dobutamine, their administration has been associated with an increased risk of death. ${ }^{26}$

The OPTIME-HF was the only study in which the effects of a PDE-I (milrinone) were assessed with a prospective, double-blind, parallel group, randomized, placebo-controlled design. The trial included 951 patients admitted for an exacerbation of HF. ${ }^{31}$ No difference was found between the milrinone and placebo groups with respect of the total number of days hospitalized for cardiovascular causes, inhospital mortality, 60-day mortality, or the composite incidence of death or readmission. However, patients on milrinone, compared with those on placebo, had more treatment failures caused by adverse events as well as episodes of sustained hypotension requiring intervention $(10.7 \%$ vs $3.2 \% ; P<.001)$ and new atrial arrhythmias $(4.6 \%$ vs $1.5 \% ; P=.004) .{ }^{31}$ A further analysis showed that milrinone may increase mortality in the patients with concomitant coronary artery disease with no effect on outcomes in patients with nonischemic cardiomyopathy. ${ }^{32}$ 
A major limitation of OPTIME-HF is that, to have a placebo-controlled trial, patients with an indication for IV inotropic therapy were excluded from the trial. Thus, the patients who should have gained the greatest benefit from inotropic therapy (ie, with shock or hypotension) were excluded from the study. This was also shown by the relatively high blood pressure of the patients studied (120/ $71 \mathrm{~mm} \mathrm{Hg}$ ) as well as by the low proportion of patients on concomitant dobutamine therapy $(9.3 \%$ on placebo vs $11.5 \%$ on dobutamine). ${ }^{31}$

An increase in mortality in the patients on PDE-Is has been consistently shown by long-term studies with the oral agents. ${ }^{33-35}$ However, these data were collected before the introduction of $\beta$-blockers in HF treatment; and lower doses of PDE-Is might have had a better benefit-to-risk ratio. However, even a more recent placebo-controlled trial in which the effects of low doses of oral enoximone have been assessed in 1854 patients with advanced HF on current medical treatment, including $\beta$-blockers, has failed to show any effect of enoximone on mortality, hospitalizations, symptoms, and exercise capacity. ${ }^{36}$ Although these neutral results may be interpreted as more favorable, compared with previous negative trials, they confirm the low benefit-to-risk ratio of PDE-Is in the treatment of advanced HF.

\section{Calcium sensitizers}

Levosimendan is the prototype of calcium sensitizers. It has 2 main mechanisms of action: calcium sensitization of the contractile proteins and opening of adenosine triphosphate (ATP)-dependent $\mathrm{K}^{+}$channels. Enhanced $\mathrm{Ca}^{2+}$ binding by troponin $\mathrm{C}$ may increase cardiac contractility in the absence of any increase in intracellular $\mathrm{Ca}^{2+}$ concentration, a potentially untoward mechanism increasing myocardial energy expenditure and arrhythmic risk. The opening of $\mathrm{K}^{+}$channels in vascular smooth muscle cells causes arteriolar and venous dilation. Phosphodiesterase type 3 inhibition is also present, but this effect has been described as milder compared with the other 2 mechanisms of action of this agent. ${ }^{18}$

The favorable effects on mortality of levosimendan, suggested by early trials, were not confirmed in 2 more recent randomized controlled trials: survival of patients with acute HF in need of intravenous inotropic support (SURVIVE) $^{37}$ and randomized multicenter evaluation of intravenous levosimendan efficacy versus placebo in the short-term treatment of decompensated heart failure II (REVIVE-II). ${ }^{38}$ The primary end point of REVIVE-II was the improvement in the signs and symptoms of HF at 24 hours, 48 hours, and 5 days. Levosimendan treatment was associated with a favorable effect on the primary end point $(P=.015)$ with a larger decline in brain natriuretic peptide (BNP) plasma levels and a shorter (2 days) duration of hospital stay. However, no difference in 90-day mortality was found ( 35 deaths on placebo, $12 \%$, vs 45 deaths, $15 \%$, on levosimendan; $P=.210$ ). Moreover, treatment with levosimendan was associated with higher rate of adverse effects, compared with placebo: hypotension $(50 \%$ vs $36 \%$ ), ventricular tachycardia ( $24 \%$ vs $17 \%)$, and atrial fibrillation ( $8 \%$ vs $2 \%) .{ }^{38}$

In the SURVIVE trial, 1327 patients with acute HF needing inotropic support were randomized to levosimendan or dobutamine. ${ }^{39}$ Mortality at 180 days (primary end point) was similar between the 2 study groups ( $26 \%$ with levosimendan vs $28 \%$ with dobutamine; $P=.40$ ). Brain natriuretic peptide decrease was larger in the patients assigned to levosimendan; and the rate of worsening HF was greater in the dobutamine group, whereas the rate of new onset atrial fibrillation was greater in the levosimendan group. ${ }^{37}$

Peripheral vasodilation and hypotension are potential major limitations of levosimendan. The decrease in blood pressure and the increase in heart rate from baseline were larger with levosimendan, compared with placebo, in SURVIVE. It is possible that the design of this trial favored the side effects, namely, hypotension, of levosimendan. First, an insufficient response to diuretics and/or vasodilators was an inclusion criterion of the study so that the study drug could be administered only to patients already on maximal doses of diuretics and/or vasodilators. Second, a relatively high dose of levosimendan, $12 \mu \mathrm{g} / \mathrm{kg}$ $\mathrm{IV}$, had to be administered as a bolus before the continuous infusion at $0.1 \mu \mathrm{g} / \mathrm{kg}$ per minute. ${ }^{37}$

Few data are available about oral levosimendan. In a recent randomized, double-blind, multicenter trial, 307 patients with HF (New York Heart Association [NYHA] class IIIB-IV, LVEF $\leq 30 \%$ ) on angiotensin-converting enzyme inhibitors and $\beta$-blockers were randomized to placebo or oral levosimendan (1 $\mathrm{mg}$ once or twice daily for at least 180 days). There were no differences between levosimendan and placebo in symptoms and episodes of worsening HF $(P=.567)$, but there was an improvement in the Minnesota Living with Heart Failure quality-of-life score $(P<.001)$ and a decrease in N-terminal pro-BNP $(-30 \%$ to $40 \% ; P<.001)$ in the levosimendan group. ${ }^{41}$

\section{Agents under investigation}

\section{$\mathrm{Na}^{+} / \mathrm{K}^{+}$-adenosine triphosphatase inhibitors}

Istaroxime is the prototype of a new class of agents, which have both positive inotropic activity, due to inhibition of $\mathrm{Na}^{+}-\mathrm{K}^{+}$adenosine triphosphatase (ATPase) located at the sarcolemma, with a secondary increase in cytosolic calcium concentration as well as lusitropic activity, through sarcoplasmic reticulum calcium ATPase (SERCA) activation with increased calcium uptake by the SR and improved relaxation (Table 3). ${ }^{40}$

The Haemodynamic effects of istaroxime, a novel lusitropic agent, in patients with LV systolic dysfunction 
Table 3

Inotropic agents under investigation

\begin{tabular}{|c|c|}
\hline Drug & Mechanism \\
\hline $\begin{array}{l}\mathrm{Na}^{+} / \mathrm{K}^{+} \text {-ATPase inhibitors } \\
\quad \text { Istaroxime }\end{array}$ & $\begin{array}{l}\text { Sarcolemma } \mathrm{Na}^{+}-\mathrm{K}^{+} \text {pump inhibition: cytosolic calcium increase } \\
\text { SERCA2a stimulation: increased uptake of cytosolic calcium into } \\
\text { the SR during diastole: better relaxation and increased calcium } \\
\text { release during systole }\end{array}$ \\
\hline $\begin{array}{l}\text { Cardiac myosin activators } \\
\text { Omecamtiv mecarbil }\end{array}$ & $\begin{array}{l}\text { Myosin stimulation: increased actin myosin interaction, systolic } \\
\text { ejection phase lengthening, no change in ejection rate, or intracellular } \\
\text { calcium changes }\end{array}$ \\
\hline $\begin{array}{l}\text { RyR stabilizers } \\
\text { JTV-519, S107 }\end{array}$ & Promotes RyR2/calstabin 2 interaction, no SR calcium leakage \\
\hline $\begin{array}{l}\text { SERCA2a activators } \\
\text { SERCA2a adenoassociated viral vector, other agents }\end{array}$ & $\begin{array}{l}\text { SERCA2a up-regulation: increased uptake of cytosolic calcium into the } \\
\text { SR during diastole: better relaxation and increased calcium release } \\
\text { during systole }\end{array}$ \\
\hline $\begin{array}{l}\text { Metabolic modulators } \\
\text { Perhexiline, trimetazidine, ranolazine, glucagon-like peptide } 1\end{array}$ & $\begin{array}{l}\text { Carnitine palmitoyl transferase } 1 \text { inhibition: myocardial substrate shift } \\
\text { from FFAs to glucose; other mechanisms (ranolazine, Glucagon-like Peptide-1) }\end{array}$ \\
\hline Urocortin 2 & Myocardial and vascular CRF2 receptors \\
\hline
\end{tabular}

hospitalized with exacerbation of chronic HF (HORIZON$\mathrm{HF}$ ) trial has assessed the hemodynamic effects of istaroxime in 120 patients admitted for acute HF with LVEF $35 \%$ or less and a SBP between 90 and $150 \mathrm{~mm} \mathrm{Hg}$. Patients were randomized 3:1 to a 6-hour continuous infusion of 3 different doses of istaroxime $(0.5,1.0$, and $1.5 \mu \mathrm{g} / \mathrm{kg}$ per minute) or placebo. Istaroxime compared with placebo was associated with pulmonary wedge pressure reduction (primary end point, $P<.05$ for all 3 doses), an increase in the cardiac index, and a decrease in the LV end-diastolic volume (significant only with the dose of $1.5 \mu \mathrm{g} / \mathrm{kg}$ per minute). ${ }^{41}$ Istaroxime was also associated with a dose-dependent increase in the E' velocity $(P=.043)$ and the $\mathrm{E}$ wave deceleration time $(P=.001)$, with a decrease in the $\mathrm{E} / \mathrm{E}$ ' ratio $(P=.047){ }^{42}$ These favorable hemodynamic effects were attended, as a peculiarity of this agent among the other inotropic drugs, by an increase in the blood pressure, potentially useful for the treatment of the patients with hypotension, and a decrease in heart rate, potentially useful in patients with coronary artery disease as a mechanism to improve coronary blood flow and reduce myocardial oxygen consumption. More studies are needed to verify the effects of this agent in patients with HF and low cardiac output.

\section{Cardiac myosin activators}

These agents act on cardiac myosin enhancing the transition of the actin-myosin complex from the weakly bound to the strongly bound configuration, thus increasing the number of myosin heads interacting with the actin filament. The rate of nonproductive ATP hydrolysis is also reduced. Increased actin-myosin interaction prolongs the duration of systole and, hence, increases stroke volume in the absence of any change in intracellular calcium concentrations and in the velocity of myocardial contraction. This results in an improvement in myocardial systolic function in the absence of the untoward effects of increased intracellular cAMP and calcium concentrations. ${ }^{11,43}$
The IV infusion of the myosin activator omecamtiv mecarbil in 2 experimental models of pacing-induced LV systolic dysfunction, caused by myocardial infarction or chronic pressure overload with LV hypertrophy, respectively, was associated with a $44 \% \pm 6.5 \%$ increase in stroke volume and a $22 \% \pm 2.8 \%$ increase in cardiac output with a concomitant $15 \% \pm 3.0 \%$ reduction in heart rate, no change in blood pressure, and a decline in LV end-diastolic pressure. Differently from dobutamine, omecamtiv mecarbil did not increase $\mathrm{LV} \mathrm{dP} / \mathrm{dt}$ but increased LV systolic ejection time $(+26 \% \pm 2.9 \%)$ and did not increase myocardial oxygen consumption. ${ }^{44}$ These results in animal models have been confirmed by preliminary findings in patients with chronic HF and low LVEF showing a concentration-dependent increase in LV systolic ejection time, stroke volume, and cardiac output and a reduction in heart rate after omecamtiv mecarbil administration. ${ }^{43}$

Despite the favorable effects on myocardial oxygen consumption, lengthening of the systolic ejection time may have untoward effects on coronary perfusion because it may cause a decrease in the diastolic time duration. However, no untoward effects on exercise tolerance have been shown after omecamtiv mecarbil administration to patients with ischemic cardiomyopathy in a study presented at the 2009 European Society of Cardiology congress. ${ }^{45}$ Omecamtiv mecarbil looks to be a potentially promising agent for the treatment for patients with HF, and a program of clinical studies is ongoing. ${ }^{43}$

\section{Ryanodine receptor stabilizers}

In the failing heart, sympathetic activation leads to excessive protein kinase A-mediated ryanodine receptor (RyR) 2 phosphorylation, dissociation of the stabilizing unit calstabin 2 (also known as FKBP12.6), and calcium leakage from the SR. Therefore, stabilization of RyR2 may represent a novel therapeutic strategy for the treatment of HF. ${ }^{46,47}$ The 1,4-benzothiazepines JTV-519 
and S107 are agents that stabilize the RyR2-calstabin 2 interaction and prevent SR calcium leakage. In an animal models of myocardial infarction - and pacing-induced HF, the 1,4-benzothiazepine derivative JTV-519 increased calstabin 2 binding to RyR2, inhibited SR calcium leakage, and prevented the deterioration of cardiac function. ${ }^{48}$ These results suggest that these agents may be useful for the treatment of HF, including HF caused by predominant diastolic dysfunction. Further investigations are needed.

\section{SERCA2a activators}

Sarcoplasmic reticulum calcium ATPase (SERCA) 2a is the enzyme responsible for the reuptake of calcium into the SR during the early diastolic phase. It is down-regulated in the failing heart, and this accounts for the increased free intracytoplasmatic calcium and reduced calcium storage in the SR with reduced calcium release from the SR and, hence, less force of contraction, at the next systole. These mechanisms cause impaired cardiac function and tachyarrhythmias. Sarcoplasmic reticulum calcium ATPase 2a has, thus, become a major target of HF treatment.

An adenoassociated viral vector carrying the gene for SERCA2a has been studied by intracoronary injections in 9 patients with advanced HF (NYHA class III/IV, LVEF $\leq 30 \%$, peak oxygen consumption per unit time $\left[\mathrm{VO}_{2}\right]<16 \mathrm{~mL} / \mathrm{kg}$ per minute, with maximal pharmacologic and device therapy). ${ }^{49}$ At 6- to 12-month follow-up, adeno-associated viral vector/ SERCA2a demonstrated evidence of biologic activity across several symptomatic, functional, and structural efficacy end points without adverse effects. These findings have supported the initiation of the phase 2 double-blind, placebo-controlled portion of the study.

In addition to gene therapy, a class of novel small molecules, acting as allosteric compounds, is under development and has been shown to modulate SERCA2a activity and increase peak $\mathrm{VO}_{2}$ and contractility without increasing energy use, making them important candidates as new IV inotropic drugs. ${ }^{11}$

\section{Metabolic modulators}

These agents cause a shift in energy use from free fatty acids (FFAs) to glucose. Free fatty acids are the preferred metabolic substrate used by the heart to produce energy. Their oxidation generates a greater amount of ATP compared with the glycolytic pathway, although a greater amount of oxygen is also required; and thus, the ATP/ oxygen ratio, that is, the efficiency of the process, is lower when FFAs, rather than glucose, are used. ${ }^{50}$ Metabolic modulators were initially developed as a treatment for patients with recurrent episodes of angina. However, these drugs became of interest also for HF treatment as a shift in myocardial metabolism from predominant FFAs to glucose uptake is potentially beneficial also in these patients.
Perhexiline is an inhibitor of carnitine palmitoyl transferase 1, an enzyme playing a critical role for mitochondrial FFA uptake. It has been associated with serious adverse effects, such as hepatotoxicity and peripheral neuropathy, which can be, however, avoided by careful dose titration and monitoring of drug plasma levels. ${ }^{51}$ Eight weeks of treatment with perhexiline were associated with an improvement in peak $\mathrm{VO}_{2}(P<.001)$, quality of life $(P=.04)$, and LVEF $(P<.001)$, with no significant adverse effects, compared with placebo. ${ }^{52}$

Other agents active on myocardial metabolism and potentially useful for HF treatment include trimetazidine and ranolazine. Trimetazidine administration has been associated with an increase in the phosphocreatine to ATP ratio, assessed by 31P-magnetic resonance spectroscopy, with a reduced FFAs oxidation and unchanged myocardial oxidative rate, implying increased glucose oxidation. ${ }^{53,54}$ Favorable effects on multiple parameters related to $\mathrm{LV}$ function and exercise capacity have been shown in relatively small studies. In a recent meta-analysis of 17 placebocontrolled, randomized trials including 955 patients with $\mathrm{HF}$, trimetazidine administration has been associated with an improvement in LVEF, a decrease in LV end-systolic volume, and an improvement in NYHA functional class and exercise duration. Trimetazidine administration was also associated with a lower all-cause mortality (relative risk, $0.29 ; 95 \%$ confidence interval $[\mathrm{CI}], 0.17-0.49)$ and a lower rate of cardiovascular events and hospitalizations. ${ }^{55}$ These data were, however, collected mainly in relatively small studies, often conducted in single centers. More studies, namely, larger multicenter randomized clinical trials, are warranted to confirm its effects in HF.

Ranolazine acts through the inhibition of late sodium channel current, thus preventing intracellular calcium overload during myocardial ischemia, and through the inhibition of FFAs oxidation. It is now indicated for the treatment of angina. However, its beneficial effects on LV diastolic function, likely mediated by the prevention of intracellular $\mathrm{Ca}^{2+}$ overload, have also been shown. ${ }^{56,57} \mathrm{It}$ may, therefore, be potentially useful for the treatment of $\mathrm{HF}$, also when caused by LV diastolic dysfunction. Beneficial effects on LV remodeling and myocardial fibrosis have also been shown in experimental models. ${ }^{58}$ Differently from dobutamine, it has increased myocardial mechanical efficiency in a dog model of HF. ${ }^{59}$

Glucagon-like peptide 1 is a relatively new antidiabetic agents. Beneficial effects of its administration on LVEF and exercise tolerance have been shown in patients with HF in some, ${ }^{60,61}$ but not all, ${ }^{62}$ of the studies. As with the previous compounds, a larger controlled trial with clinical end points is needed.

\section{Urocortin}

Urocortin is a vasoactive peptide belonging to the corticotrophin-releasing factor (CRF) peptide family. ${ }^{63}$ 
Corticotrophin-releasing factor and the urocortins 1, 2, and 3 act through G-protein-coupled receptor subtypes, CRF1 and CRF2. Corticotrophin-releasing factor 1 receptors are localized almost exclusively in the central nervous system, whereas CRF2 receptors are present both in the brain and in peripheral tissues, including the myocardium and blood vessels where they are strongly expressed. Differently from urocortin 1 , which binds similarly to both receptor subtypes, urocortins 2 and 3 are selective for the CRF2 receptors. ${ }^{64,65}$ The administration of urocortins, namely, urocortins 2 and 3 , in experimental models of HF has been associated with an increase in cardiac output and a decline in peripheral resistance, left atrial pressure, and mean arterial pressure. It has induced a persistent, dose-dependent decrease in plasma vasopressin, renin activity, aldosterone, natriuretic peptides, and endothelin 1 plasma levels, with an acute rise in adrenocorticotrophic hormone and cortisol levels. Lastly, a dose-dependent, sustained increase in diuresis, natriuresis, and creatinine clearance was found. ${ }^{65-67} \mathrm{~A}$ favorable interaction with diuretic treatment with increased diuretic responsiveness and blunting of furosemide-induced renin increase has also been shown. ${ }^{68}$ Urocortin 3 (stresscopin) is now undergoing further assessment in larger clinical trials in patients with HF.

\section{Conclusions and future perspectives}

Treatment of patients with acutely decompensated HF and signs of low cardiac output and end-organ dysfunction remains one of the major challenges of current cardiovascular therapy. Current inotropic agents have short-term hemodynamic effects but may also favor arrhythmias, myocardial ischemia, and cardiac damage. Inotropic agents have evolved through the enthusiasm for increased contractility and the disappointment from increased mortality. New, potentially favorable mechanisms of action include a reduction in heart rate, a lack of hypotensive effects, and more efficient myocardial contraction with less oxygen consumption. New agents seem to possess some, if not all, of these characteristics. Only properly designed controlled studies, also powered to assess medium- and long-term effects and safety, will show if newer inotropic agents may improve the treatment- of patients with advanced HF.

\section{Statement of Conflict of Interest}

All authors declare that there is no conflicts of interest with respect of the topics of the present article.

\section{References}

1. Jessup M, Abraham WT, Casey DE, et al: 2009 focused update: ACCF/AHA Guidelines for the Diagnosis and Management of Heart Failure in Adults: a report of the American College of Cardiology Foundation/American Heart Association Task Force on Practice
Guidelines: developed in collaboration with the International Society for Heart and Lung Transplantation. Circulation 2009;119: 1977-2016.

2. Dickstein K, Cohen-Solal A, Filippatos G, et al: ESC guidelines for the diagnosis and treatment of acute and chronic heart failure 2008: the Task Force for the diagnosis and treatment of acute and chronic heart failure 2008 of the European Society of Cardiology. Developed in collaboration with the Heart Failure Association of the ESC and endorsed by the European Society of Intensive Care Medicine (ESICM). Eur J Heart Fail 2008;10:933-989.

3. Lindenfeld J, Albert NM, Boehmer JP, et al: Executive summary: HFSA 2010 Comprehensive Heart Failure Practice Guideline. J Card Fail 2010;16:475-539.

4. MacIntyre K, Capewell S, Stewart S, et al: Evidence of improving prognosis in heart failure: trends in case fatality in 66547 patients hospitalized between 1986 and 1995. Circulation 2000;102: 1126-1131.

5. Metra M, Ponikowski P, Dickstein K, et al: Advanced chronic heart failure: a position statement from the Study Group on Advanced Heart Failure of the Heart Failure Association of the European Society of Cardiology. Eur J Heart Fail 2007;9:684-694.

6. Metra M, Brutsaert DL, Dei Cas L, et al: Acute heart failure: epidemiology, epidemiology, classification, and pathophysiology. In: Tubaro M, Danchin M, Filippatos G, Goldstein P, Vranckx P, Zahger D, editors. The ESC textbook of intensive and acute cardiac care. Oxford University Press; 2010. p. 471-482.

7. Stevenson LW: Are hemodynamic goals viable in tailoring heart failure therapy? Hemodynamic goals are relevant. Circulation 2006;113:1020-1027.

8. Felker GM, O'Connor CM: Inotropic therapy for heart failure: an evidence-based approach. Am Heart J 2001;142:393-401.

9. Stevenson LW: Clinical use of inotropic therapy for heart failure: looking backward or forward? Part I: inotropic infusions during hospitalization. Circulation 2003;108:367-372.

10. Gheorghiade M, Pang PS: Acute heart failure syndromes. J Am Coll Cardiol 2009;53:557-573.

11. Teerlink JR, Metra M, Zacà V, et al: Agents with inotropic properties for the management of acute heart failure syndromes. Traditional agents and beyond. Heart Fail Rev 2009;14:243-253.

12. Cotter G, Felker GM, Adams KF, et al: The pathophysiology of acute heart failure-is it all about fluid accumulation? Am Heart J 2008;155:9-18.

13. Metra M, Dei Cas L, Bristow MR: The pathophysiology of acute heart failure - it is a lot about fluid accumulation. Am Heart J 2008;155:1-5.

14. Zile MR, Bennett TD, St John Sutton M, et al: Transition from chronic compensated to acute decompensated heart failure: pathophysiological insights obtained from continuous monitoring of intracardiac pressures. Circulation 2008;118:1433-1441.

15. Nohria A, Lewis E, Stevenson LW: Medical management of advanced heart failure. JAMA 2002;287:628-640.

16. Gheorghiade M, Abraham WT, Albert NM, et al: Systolic blood pressure at admission, clinical characteristics, and outcomes in patients hospitalized with acute heart failure. JAMA 2006;296: 2217-2226.

17. Nauman DJ, Hershberger RE: The use of positive inotropes in endof-life heart failure care. Curr Heart Fail Rep 2007;4:158-163.

18. Nieminen MS, Böhm M, Cowie MR, et al: Executive summary of the guidelines on the diagnosis and treatment of acute heart failure: the Task Force on Acute Heart Failure of the European Society of Cardiology. Eur Heart J 2005;26:384-416.

19. Nieminen MS, Brutsaert D, Dickstein K, et al: EuroHeart Failure Survey II (Eheart failureS II): a survey on hospitalized acute heart failure patients: description of population. Eur Heart J 2006;27: 2725-2736.

20. Abraham WT, Adams KF, Fonarow GC, et al: In-hospital mortality in patients with acute decompensated heart failure requiring 
intravenous vasoactive medications: an analysis from the Acute Decompensated Heart Failure National Registry (ADHERE). J Am Coll Cardiol 2005;46:57-64.

21. Leier CV, Binkley PF: Parenteral inotropic support for advanced congestive heart failure. Prog Cardiovasc Dis 1998;41:207-224.

22. Metra M, Nodari S, D'Aloia A: Beta-blocker therapy influences the hemodynamic response to inotropic agents in patients with heart failure: a randomized comparison of dobutamine and enoximone before and after chronic treatment with metoprolol or carvedilol. J Am Coll Cardiol 2002;40:1248-1258.

23. Fowler MB, Laser JA, Hopkins GL, et al: Assessment of the betaadrenergic receptor pathway in the intact failing human heart: progressive receptor down-regulation and subsensitivity to agonist response. Circulation 1986;74:1290-1302.

24. Unverferth DA, Blanford M, Kates RE, et al: Tolerance to dobutamine after a 72 hour continuous infusion. Am J Med 1980; 69:262-266.

25. O'Connor CM, Gattis WA, Uretsky BF, et al: Continuous intravenous dobutamine is associated with an increased risk of death in patients with advanced heart failure: insights from the Flolan International Randomized Survival Trial (FIRST). Am Heart J 1999;138:78-86.

26. Thackray S, Easthaugh J, Fremantle N, et al: The effectiveness and relative effectiveness of intravenous inotropic drugs acting through the adrenergic pathway in patients with heart failure - meta-regression analysis. Eur J Heart Fail 2002;4:515-529.

27. Maskin CS, Ocken S, Chadwick B, et al: Comparative systemic and renal effects of dopamine and angiotensin-converting enzyme inhibition with enalaprilat in patients with heart failure. Circulation 1985;72:846-852.

28. Elkayam U, Ng TM, Hatamizadeh P, et al: Renal vasodilatory action of dopamine in patients with heart failure: magnitude of effect and site of action. Circulation 2008;117:200-205.

29. Giamouzis G, Butler J, Starling RC, et al: Impact of dopamine infusion on renal function in hospitalized heart failure patients: results of the Dopamine in Acute Decompensated Heart Failure (DAD-HF) Trial. J Card Fail 2010;16:922-930.

30. Friedrich JO, Adhikari N, Herridge MS, et al: Meta-analysis: lowdose dopamine increases urine output but does not prevent renal dysfunction or death. Ann Intern Med 2005;142:510-524.

31. Cuffe MS, Califf RM, Adams KF Jr, et al: Short-term intravenous milrinone for acute exacerbation of chronic heart failure: a randomized controlled trial. JAMA 2002;287:1541-1547.

32. Felker GM, Benza RL, Chandler AB, et al: Heart failure etiology and response to milrinone in decompensated heart failure: results from the OPTIME-CHF study. J Am Coll Cardiol 2003;41:997-1003.

33. Packer M, Carver JR, Rodeheffer RJ, et al: Effect of oral milrinone on mortality in severe chronic heart failure. The PROMISE Study Research Group. N Engl J Med 1991;325:1468-1475.

34. Cohn JN, Goldstein SO, Greenberg BH, et al: A dose-dependent increase in mortality with vesnarinone among patients with severe heart failure. Vesnarinone Trial Investigators. N Engl J Med 1998; 339:1810-1816.

35. Uretsky BF, Jessup M, Konstam MA, et al: Multicenter trial of oral enoximone in patients with moderate to moderately severe congestive heart failure. Lack of benefit compared with placebo. Enoximone Multicenter Trial Group. Circulation 1990;82:774-780.

36. Metra M, Eichhorn E, Abraham WT, et al: Effects of low-dose oral enoximone administration on mortality, morbidity, and exercise capacity in patients with advanced heart failure: the randomized, double-blind, placebo-controlled, parallel group ESSENTIAL trials. Eur Heart J 2009;30:3015-3026.

37. Mebazaa A, Nieminen MS, Packer M, et al: Levosimendan vs dobutamine for patients with acute decompensated heart failure: the SURVIVE Randomized Trial. JAMA 2007;297:1883-1891.

38. Cleland JG, Freemantle N, Coletta AP, et al: Clinical trials update from the American Heart Association: REPAIR-AMI, ASTAMI,
JELIS, MEGA, REVIVE-II, SURVIVE, and PROACTIVE. Eur J Heart Fail 2006;8:105-110.

39. Mebazaa A, Nieminen MS, Packer M, et al: Levosimendan vs dobutamine for patients with acute decompensated heart failure. The SURVIVE randomized trial. JAMA 2007;297:1883-1891.

40. Khan $\mathrm{H}$, Metra M, Blair JE, et al: Istaroxime, a first in class new chemical entity exhibiting SERCA-2 activation and Na-K-ATPase inhibition: a new promising treatment for acute heart failure syndromes? Heart Fail Rev 2009;14:277-287.

41. Shah SJ, Blair JE, Filippatos GS, et al: Effects of istaroxime on diastolic stiffness in acute heart failure syndromes: results from the Hemodynamic, Echocardiographic, and Neurohormonal Effects of Istaroxime, a Novel Intravenous Inotropic and Lusitropic Agent: a Randomized Controlled Trial in Patients Hospitalized with Heart Failure (HORIZON-HF) trial. Am Heart J 2009;157:1035-1041.

42. Gheorghiade M, Blair JE, Filippatos GS, et al: Hemodynamic, echocardiographic, and neurohormonal effects of istaroxime, a novel intravenous inotropic and lusitropic agent: a randomized controlled trial in patients hospitalized with heart failure. J Am Coll Cardiol 2008;51:2276-2285.

43. Teerlink JR: A novel approach to improve cardiac performance: cardiac myosin activators. Heart Fail Rev 2009;14:289-298.

44. Shen YT, Malik FI, Zhao X, et al: Improvement of cardiac function by a cardiac myosin activator in conscious dogs with systolic heart failure. Circ Heart Fail 2010;3:522-527.

45. Bax JJ, Casadei B, Di Mario C, et al: Highlights of the 2009 scientific sessions of the European Society of Cardiology. J Am Coll Cardiol 2009;54:2447-2458.

46. Hasenfuss G, Seidler T: Treatment of heart failure through stabilization of the cardiac ryanodine receptor. Circulation 2003;107:378-380.

47. Lompré AM, Hajjar RJ, Harding SE, et al: Ca2+ cycling and new therapeutic approaches for heart failure. Circulation 2010;121:822-830.

48. Yano M, Kobayashi S, Kohno M, et al: FKBP12.6-mediated stabilization of calcium-release channel (ryanodine receptor) as a novel therapeutic strategy against heart failure. Circulation 2003; 107:477-484.

49. Jaski BE, Jessup ML, Mancini DM, et al: Calcium upregulation by percutaneous administration of gene therapy in cardiac disease (CUPID Trial), a first-in-human phase 1/2 clinical trial. J Card Fail 2009;15:171-181.

50. Lee L, Horowitz J, Frenneaux M: Metabolic manipulation in ischaemic heart disease, a novel approach to treatment. Eur Heart J 2004;25:634-641.

51. Phan TT, Shivu GN, Choudhury A, et al: Multi-centre experience on the use of perhexiline in chronic heart failure and refractory angina: old drug, new hope. Eur J Heart Fail 2009;11:881-886.

52. Lee L, Campbell R, Scheuermann-Freestone M, et al: Metabolic modulation with perhexiline in chronic heart failure: a randomized, controlled trial of short-term use of a novel treatment. Circulation 2005;112:3280-3288.

53. Fragasso G, Perseghin G, De Cobelli F, et al: Effects of metabolic modulation by trimetazidine on left ventricular function and phosphocreatine/adenosine triphosphate ratio in patients with heart failure. Eur Heart J 2006;27:942-948.

54. Tuunanen H, Engblom E, Naum A, et al: Trimetazidine, a metabolic modulator, has cardiac and extracardiac benefits in idiopathic dilated cardiomyopathy. Circulation 2008;118:1250-1258.

55. Gao D, Ning N, Niu X, et al: Trimetazidine: a meta-analysis of randomised controlled trials in heart failure. Heart 2011;97:278-286.

56. Sossalla S, Wagner S, Rasenack EC, et al: Ranolazine improves diastolic dysfunction in isolated myocardium from failing human hearts - role of late sodium current and intracellular ion accumulation. J Mol Cell Cardiol 2008;45:32-43.

57. Wu Y, Song Y, Belardinelli L, et al: The late $\mathrm{Na}+$ current (INa) inhibitor ranolazine attenuates effects of palmitoyl-L-carnitine to increase late $\mathrm{INa}$ and cause ventricular diastolic dysfunction. J Pharmacol Exp Ther 2009;330:550-557. 
58. Rastogi S, Sharov VG, Mishra S, et al: Ranolazine combined with enalapril or metoprolol prevents progressive LV dysfunction and remodeling in dogs with moderate heart failure. Am J Physiol Heart Circ Physiol 2008;295:H2149-H2155.

59. Chandler MP, Stanley WC, Morita H, et al: Short-term treatment with ranolazine improves mechanical efficiency in dogs with chronic heart failure. Circ Res 2002;91:278-280.

60. Nikolaidis LA, Elahi D, Hentosz T, et al: Recombinant glucagon-like peptide-1 increases myocardial glucose uptake and improves left ventricular performance in conscious dogs with pacing-induced dilated cardiomyopathy. Circulation 2004;110:955-961.

61. Sokos GG, Nikolaidis LA, Mankad S, et al: Glucagon-like peptide-1 infusion improves left ventricular ejection fraction and functional status in patients with chronic heart failure. J Card Fail 2006;12:694-699.

62. Halbirk M, Nørrelund H, Møller N, et al: Cardiovascular and metabolic effects of 48-h glucagon-like peptide-1 infusion in compensated chronic patients with heart failure. Am J Physiol Heart Circ Physiol 2010;298:H1096-H1102.
63. Chang CL, Hsu SY: Ancient evolution of stress-regulating peptides in vertebrates. Peptides 2004;25:1681-1688.

64. Vaughan J, Donaldson C, Bittencourt J, et al: Urocortin, a mammalian neuropeptide related to fish urotensin I and to corticotropin-releasing factor. Nature 1995;378:287-292.

65. Rademaker MT, Cameron VA, Charles CJ, et al: Integrated hemodynamic, hormonal, and renal actions of urocortin 2 in normal and paced sheep: beneficial effects in heart failure. Circulation 2005;112:3624-3632.

66. Rademaker MT, Charles CJ, Espiner EA, et al: Beneficial hemodynamic, endocrine, and renal effects of urocortin in experimental heart failure: comparison with normal sheep. J Am Coll Cardiol 2002;40:1495-1505.

67. Rademaker MT, Cameron VA, Charles CJ, et al: Urocortin 3: haemodynamic, hormonal, and renal effects in experimental heart failure. Eur Heart J 2006;27:2088-2098.

68. Rademaker MT, Charles CJ, Nicholls MG, et al: Urocortin 2 inhibits furosemide-induced activation of renin and enhances renal function and diuretic responsiveness in experimental heart failure. Circ Heart Fail 2009;2:532-540. 